\title{
Testing artificial neural network for hand gesture recognition
}

\section{JÓZSEF SÜTŐ and ŞTEFAN ONIGA}

\section{ABSTRACT.}

Neural networks are well applicable for gesture recognition. In this article we want to present the result of an artificial feed forward network for a simplified hand gesture recognition problem. In neural networks, the learning algorithm is very important because the performance of neural network depends on it. One of the most known learning algorithm is the backpropagation. There are some mathematical software which provides acceptable result for a given problem by a backpropagation based network, but in some cases a high-level programming language implemented program can provide better solution. The main topics of the article cover the structure of the test environment, the mathematical background of the implemented methods, some programming remarks and the test results.

Acknowledgement. The research was supported by the European Union and the State of $=$ Hungary, co-financed by the European Social Fund in the framework of TAMOP 4.2.4.A/2-11-1-2012-0001 "National Excellence Program -

Elaborating and operating an inland student and researcher personal support system convergence program".

The used devices and development accessories was financed by

TAMOP-4.2.2.C-11/1/KONV-2012-0001 project. The project has been supported by the European Union, co-financed by the European Social Fund.

\section{REFERENCES}

[1] Analog Devices, ADXL 3453 axis digital accelerometer, Rev. D., 2009

[2] Beale, M. H., Hagan, M. T., Demuth, H. B., Neural network toolbox users guide, The MathWork Inc., United States of America, 2013

[3] Hagan, M. T., Demuth, H. B. and Beale, M., Neural network design, PWS Publishing Company, United States of America, 1996

[4] Hagan, M. T. and Menhaj, M. B., Training feedforward networks with the Marquardt algorithm, in Neural Networks, IEEE Transactions, Nov., 1994, 989-993

[5] Haykin, S., Neural networks. A comprehensive foundation. Second edition, McMaster University, Hamilton, Ontario, Canada, 1999

[6] Hines, L. H. and Carnevale, N. T., The NEURON simulation environment, Neural Computation, 9 (1997), No. 6, 1179-1209

[7] Homik, K., Approximation capabilities of multilayer feedforward networks, Neural network, 4 (1991), 251-257

[8] Makino, T., A discrete event neural network simulator for general neuron models, Neural Computing \& Applications, 11 (2003), $210-223$

[9] Nguyen, D. and Widrow, B., Improving the learning speed of 2-layer neural networks by choosing initial values of the adaptive weights, in Neural Networks, 1990 IJCNN International Joint Conference, June 17-21, 1990, 21-26

[10] Oniga, S. and Orha, I., Hardware implemented neural networks used for hand gestures recognition, Carpathian Journal of Electronic and Computer Engineering, 4 (2011), 93-96

[11] Peretto, P., An introduction to the modeling of neural networks, Cambridge University Press, Cambridge, 1992

[12] Stroustrup, B., The C++ programming language. Third edition, AT\&T Company, New Jersey, 1997

[13] Zell, A., Mache, N., Sommer, T. and Korb, T., Recent developments of the SNNS neural network simulator, in SPIE Proceedings, Applications of Artificial Neural Networks II, August 1, 1991

[14] Zell, A., Mache, N., Hubner, R., Mamier, G., Vogt, M., Schmalzl, M. and Herrmann, K. U., SNNS (Stuttgart neural network simulator), Neural network Simulation Environments, 254 (1994), 165-168

DEPARTMENT OF INFORMATICS

UNIVERSITY OF DEBRECEN

KASSAI 26, 4010 DebreCEN, HUNGARY

E-mail address: sutojozsef001@gmail.com

E-mail address: istvan.oniga@inf.unideb.hu

* Dedicated to Professor Emeritus Constantin Corduneanu on the occasion of his 85th birthday

Received: 30.10.2013; In revised form: 20.11.2013; Accepted: 23.11.2013

2010 Mathematics Subject Classification. 68T10, 68-04.

Key words and phrases. Hand gesture recognition, artificial neural network, feed forward, $\mathrm{C}++$, object oriented programming. 